\title{
Role of the novel cytokine IL-37 in inflammations and tumors of human reproductive system
}

\author{
Jingzhe Zhao ${ }^{1}$, Lin Qiu ${ }^{1}$, Yunxin Xü ${ }^{1}$, Yien Xu' ${ }^{1}$, Yanxian Guo ${ }^{1}$, Peng Li ${ }^{1}$, Zhangquan Chen ${ }^{2}$, Hongsheng Guo ${ }^{1}$ and Sen Wang ${ }^{*}$ \\ ${ }^{1}$ Histology and embryology teaching and research section, Basic medicine department of Guangdong medical university, Guangdong province, China \\ ${ }^{2}$ School of laboratory medicine of Guangdong medical university, Guangdong province, China
}

\begin{abstract}
IL-37 is one of the newest members of interleukin family and is also one of the most popular cytokine. It has been identified as an inhibitor of both innate and adaptive immunity in those most recently presented researches. However, the biological properties and the related mechanism of IL-37 haven't been fully characterized. Although changes of IL-37 levels in reproductive system diseases and its role in tumors were different even potentially opposite, clues have shown that IL-37 is valuable for the diagnosis and therapy of inflammatory diseases and tumors. IL-37 plays mainly an anti-inflammatory role in Adenomyosis and Endometriosis and an anti-cancer role in cervical cancer and breast cancer. Recent controversial focuses are on the areas of tumors and ovarian diseases. In this review, the roles of IL-37 in reproductive system diseases will be presented.
\end{abstract}

\section{Introduction}

Interleukin 37 (IL-37) is a newly discovered anti-inflammatory cytokine and was renamed in 2010 [1]. IL-37 is the seventh member of IL-1 family (IL-1F7) and is one of the most popular cytokines in the current studies. More than two hundred papers were published in the last 7 years comparing with nine studies before 2010. IL-37 has been identified as an inhibitor of innate and adaptive immunity in many inflammatory diseases, such as lupus erythematosus [2,3],myocarditis [4], hepatitis [5], colitis [6] and so on. Additionally, several studies also showed good applicational prospects of IL-37 in tumor diagnosis. In recent years, the incidence of inflammation and tumors increase in the reproductive system diseases year by year which has caused a major harm to human health. IL-37 has been initially found to correlate with diseases such as adenomyosis [7], endometriosis [8,9], cervical cancer [10,11], ovarian cancer [12], breast cancer [13], etc. But it is a pity that it lacks the systemic description of the role of IL-37 in human reproductive system. Here, this paper will focus on the role ofIL-37 in reproductive system diseases.

\section{IL-37 gene and its biological functions}

Human IL-37 gene is located on the chromosome 2 and expresses a 17-24KD protein. The alternative splicing formed 5 subtypes of IL-37: IL-37a-e. IL-37b is regarded currently as the most significant isoform which contains 6exonsof IL-37 [14]. Analogously as other IL-1 family members, IL-37b lacks the typical signal peptide. But No. 1 and No. 2 exon in $\mathrm{N}$-terminal codes a pre-structure domain which contains the splice site of caspase-1. The process of IL-37 maturation depends on the spitting effect of caspase-1 which transforms the precursor into maturity $[1,15]$. There is a distinctive code by exon 3 in the $\mathrm{N}$ terminal on IL-37a. The coding region of IL-37a and IL-37d contain the exon 4 , which encodes the IL- 1 family-specific $\beta$-clover structure. It can be inferred that IL-37a and IL-37d may have biological function which need further research. IL-37c and IL-37e both lacks exon 2 or exon 4, thus they may presumably be non-functional [16].
The expression and distribution of these five subtypes are different in human tissues and cells (Figure 1). IL-37 usually refers to IL-37b. IL-37 shows low expressions in healthy tissues and normal cells, and its expressions are significantly enhanced when stimulated by inflammation. Most cytokines in the IL-1 family are pro-inflammatory except IL-37. Though the effects of IL-37 have not been fully elucidated, current studies provide some features of IL-37.

Firstly, IL-37serves as an anti-inflammatory cytokine via combining with IL-18BP partly [17-19]. IL-18 was once described as an IFN- $\gamma$ inducible factor that cleaves into a biologically active molecule under caspase-1 [20]. Besides this,IL-18 receptor complex (IL-18R) consists of a heterodimer containing two chains that trigger activation of caspase-1 through TLRs [21]. Among the IL-18R, The IL-18R a chain is required for ligand binding, while $\beta$ chain is required for signal transduction. IL18 alone induces only small amounts of IFN- $\gamma$, but its combination with IL-12 induces T cells to produce high levels of IFN- $\gamma$ which enhances the cytotoxicity of NK cells and promotes $\mathrm{TH} 1$ or $\mathrm{TH} 2$ cell responses [22]. IL-37 has two conserved amino acid residues (Glu-35 and Lys124), which is similar to the two conserved residues (Glu-35 and Lys-89) of IL-18 (interleukin 18). IL-37 does not interact directly with IL-18R $\beta$, but binds IL-18Ra and IL-18BP extracellularly, whereas IL-18BP is a natural antagonist of IL-18 [23]. Thus IL-37 can bind to IL-18BP and high-regulate the ability of IL-18BP to inhibit IL-18, thereby reducing the downstream signal transduction of IL-18R [17-19]. Ultimately IL37 can be delivered via this pathway to exert anti-inflammatory effect.

*Correspondence to: Sen Wang, Histology and embryology teaching and research section, Basic medicine department of Guangdong medical university, Guangdong province, China, Tel: +86-769-2289-6383; E-mail: wangsen@gdmu.edu.cn

Key words: IL-37, Inflammation, Tumor, Reproductive system, Cytokine

Received: October 09, 2018; Accepted: October 22, 2018; Published: October 26,2018 


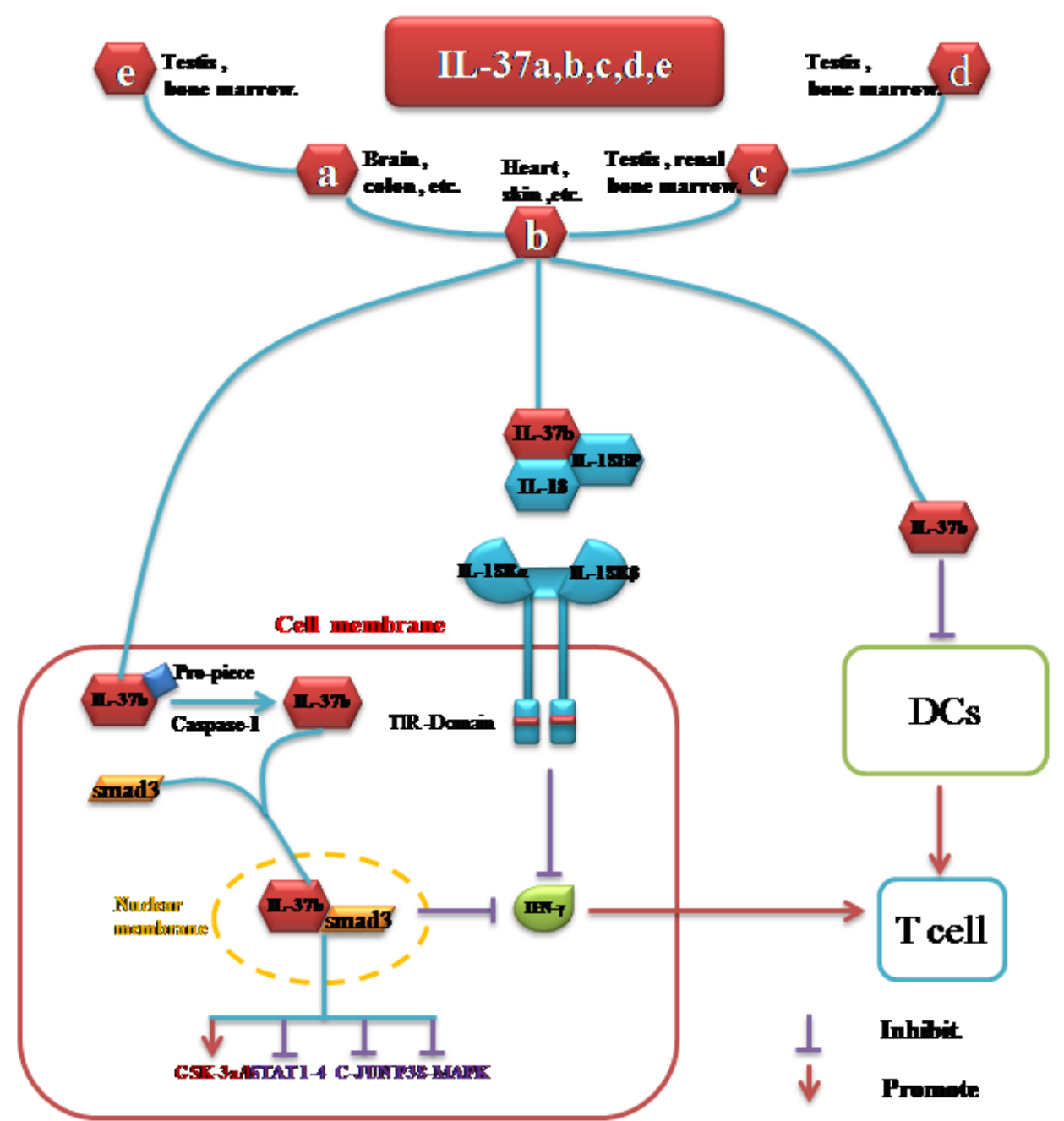

Figure 1. IL-37 expression and its role in diseases. Firstly, IL-37 (IL-1F7) binds to IL-18BP and enhances the ability of IL-18BP to inhibit IL-18, thereby reducing the downstream signal transduction of IL-18R. Secondly, IL-37not only inhibits the activity of CD68 and MHCII molecules of DCs, but also inhibits the activation of Lipopolysaccharides-induced CD11 ${ }^{+}$DCs. Therefore, IL-37 reduces the T-cell-mediated inflammatory response by down-regulating activity of DC. Furthermore, inhibition of STAT1, C-JUN, P38-MAPK and promotion of GSK-3a/b phosphorylation take part in the anti-inflammatory function of IL-37/Smad3 complex which could also inhibit DCs by enhancing the ability of TGF- $\beta$

IL-18BP: Interleukin 18 Binding Protein; CD68: Cluster of Differentiation 68; MHCII: Major Histocompatibility Complex II; DCs: Dendritic Cells; STAT1: Signal Transducer and Activator of Transcription 1; C-JUN: a member of the transcription factor activator protein-1 family; TGF- $\beta$ : Transforming Growth Factor beta; GSK-3a/b: Glycogen Synthase Kinase 3a/b; PI3K/AKT/mTOR: phosphoinositide 3-kinase/ serine-threonine kinase/ mechanistic Target Of Rapamycin

Secondly, IL-37 down-regulates the activity of Dendritic Cells (DCs) who play an important regulatory role in the immune response process [1]. IL-37 is found to not only inhibit the activity of CD68 (Cluster of Differentiation 68) and MHCII (major histocompatibility complex II) molecules of DCs, but also inhibit the activation of Lipopolysaccharides-induced CD11 ${ }^{+}$DCs. Therefore, IL-37 reduces the T-cell-mediated inflammatory response by down-regulating the activity of DCs [1].

Furthermore, Smad3 was involved in the inflammatory inhibition of IL-37 [15,24-26]. IL-37/Smad3 complex enters the nucleus, then affects gene transcription, lastly inhibits the Toll-like receptor (TLR) which could induce the expressions of IFN- $\gamma$. When Smad3was blocked by SIS3, the inhibitory effect of IL-37b on the expression of inflammatory cytokines was also blocked. In addition, inhibition of STAT1-4 (Signal transducer and activator of transcription 1-4) phosphorylation, C-JUN (a member of the transcription factor activator protein-1 family) phosphorylation, and P38-MAPK (p38 mitogen-activated protein kinases) pathway phosphorylation, promotion of GSK-3a/b (Glycogen Synthase Kinase $3 \mathrm{a} / \mathrm{b}$ ) phosphorylation also take part in IL-37 function $[15,24]$. STAT1-4, key signaling pathway of proinflammatory cytokines are substrates of JNK. They are gathering with tyrosine phosphorylation signaling pathway to play a transcriptional regulatory role and mediate various biological reactions. IL-37/Smad3 complex can inhibit the phosphorylation of STAT1-4 and increase GSK-3 a/b phosphorylation which promotes TLR-mediated inflammatory response and attenuate the inhibitory effect of $\mathrm{T}$ cells on innate immune cell-mediated inflammatory responses [27-29]. IL-37b-Smad3 complex can also inhibit c-Jun protein and P38-MAPK phosphorylation. C-Jun is part of the pro-inflammatory transcription factor AP-1 induced by IL1. And P38- MAPK can increase NF- $\mathrm{KB}$ expression and promote its translocation into the nucleus to activate interleukin-6 (IL-6), TNF- $\alpha$ and other inflammatory factors $[1,30]$.

Finally, IL-37 is also considered as a major anti-tumor cytokine. For example, IL-37 could inhibit STAT3 expression in order to 
suppress the cell proliferation of cervical cancer [10]. In liver cancer, IL-37 inhibited PI3K/AKT/mTOR (phosphoinositide3-kinase/serinethreonine kinase/mechanistic target of rapamycin) signaling pathway and regulated the autophagy of human hepatoma cells (SMMC-7721 and Huh-7 cells) [31]. Further study showed IL-37 inhibited the migration, invasion, proliferation and colony formation of colon cancer cells through inhibiting beta-catenin [32]. However, it is still unclear whether there are other genes that could bind to IL-37 besides Smad3 and whether IL-37 has a direct effect of other genes. Above of this, these may provide some certain directions for researchers.

\section{The role of IL-37 in diseases of female reproductive system diseases}

\section{IL-37 exerts its anti-inflammation and anti-cancer function in uterus diseases}

Adenomyosis: The main pathological features of adenomyosis include that endometrial glands and stromal cells invade the myometrium. This process is accompanied by the hypertrophy and proliferation of peripheral uterine smooth muscle cell as well as the infiltration of inflammatory cells. Only one report was found by Pubmed which investigated IL-37 expression in the endometrial adenocarcinoma [7]. Remarkably decreased IL-37 level in endometrial adenocarcinoma of adenomyosis was found. The results suggested that abnormal inflammatory response may occur in the endometrium of patients with adenomyosis. Therefore, increased IL-37 expression may have a positive effect on the treatment of adenomyosis.

Endometriosis (EMs): EMs is a common gynecological and frequently-occurring disease. Jiang et al. [8] showed that the expressions of IL-37 gene and protein in ectopic and eutopic endometriosis were significantly higher than those in normal tissues. And comparing with eutopic endometrium of patients with ovarian endometriosis, the expression of IL-37 gene and protein in ectopic endometrium was remarkably increased. They speculated that IL-37 may join in the inflammatory process of endometriosis. In another study, Kaabachi $\mathrm{W}$ et al. [9] found that comparing with normal subjects, the level of IL-37 was remarkably increased in peritoneal fluid (PF) and serum of endometriosis patients. IL-37 expression of patients in PF was higher than that in serum, which is consistent with Fan's report [33].

Further study found that down-regulation of NFB mRNA expression in endometriosis contributed to increase IL-37, and elevated levels of IL-37 may hinder NFB activation in patients with endometriosis [9]. Therefore, IL-37 may have some therapeutic significance for endometriosis.

IL-37 plays mainly an anti-cancer role in cervical cancer (CC): CC is a common female carcinoma which is related with Human Papillomavirus (HPV) infection and the body's immune response to infection. In our previous study, we investigated that IL-37 inhibit STAT3 (signal transducer and activator of transcription 3) which result in suppressing the proliferation and invasion of human CC cells [10]. The anti-cancer effect of IL-37 in $\mathrm{HPV}^{+}$Hela cell was stronger than that in HPV-Hela cell. In a following-up study, Yang et al. [11] also observed a similar phenomenon. Their results showed that IL-37 treatment increased the percentage of G0/G1 cells and induced the apoptosis of Hela cells by dose and time dependent manner. IL-37 inhibited the invasion and migration of CC cells, decreased the expression of STAT3, MMP-2 and MMP-9. They eventually concluded that IL-37 is a tumor suppressor in cervical cancer cells. In light of that the disease is closely linked to virus (HPV), virus infection often causes inflammation and immunologic disorders. The relationship between IL-37 and virus will be investigated in our next study. We also speculate that IL-37 may play a role in other diseases related to virus, such as liver cancer and nasopharyngeal carcinoma. This point needs further exploration and it will be a potential direction in future.

\section{The role of IL-37 in breast diseases}

Breast cancer is one of the most common malignancies in women which seriously affect women's physical and mental health and even life-threatening. Wang et al. [13] found that the proliferation of breast cancer $4 \mathrm{~T} 1$ cells was not directly affected by IL-37. 4T1-IL37cells were injected into $\mathrm{BALB} / \mathrm{c}$ mice and retardate tumor growth. Additionally, recombinant IL-37 did not affect the proliferation of CD8(+) T cell but promoting the proliferation of CD4(+) $\mathrm{T}$ cell. Therefore, IL-37b could inhibit breast carcinoma through the modulation of tumor microenvironment and the influence on T cell activation.

\section{The role of IL-37 in ovarian diseases}

Polycystic Ovary Syndrome (PCOS): PCOS is the most common endocrine disorder in women of reproductive age and is also one of the main causes of anovulatory infertility. In a recent report, PCOS patients with free androgen index and body mass index were negatively correlated with IL-37. Further studies have confirmed that PCOS can promote inflammation. Thus, IL-37inhibited the inflammation mediated by PCOS, suggesting that IL-37 may be a potential drug for the treatment of PCOS [34].

IL-37 tends to promote epithelial ovarian cancer (EOC): EOC is one of the world's most deadly gynecological cancers. Huo et al. [12] found that poor prognosis of EOC patients was related to up-regulated IL-37 in serum. The protein level of IL-37 in serum of EOC patients was remarkably higher than that of healthy control group. Then they analyzed the correlation between serum IL-37 levels and clinical factors in patients with EOC. The results showed that IL-37 levels were significantly different in the early and late stages of EOC patients. In addition, the expression level of IL-37 was positively correlated with tumor size, lymph node metastasis and positive recurrence. There was a significant correlation between residual tumor and IL-37 levels in serum. In conclusion, their results suggest that IL-37may contribute to the development of ovarian cancer.

However, according to recent studies concerning IL-37 and tumor, most researches showed that IL-37 can inhibit tumor activity through different mechanism in colon cancer [32], lung cancer [35], cervical cancer $[10,11]$, hepatocellular carcinoma [31] and renal carcinoma [36]. The differences might be due to several reasons. Firstly, these conclusions are from different organs with different carcinogenesis mechanisms, and thus emerging as different even contrary results. Secondly, in previous study, the risk of EOC in patients with PCOS is 2.5-fold higher than that of the normal controls [37], indicating that PCOS is a promotion for EOC. IL-37 has been found to inhibit PCOS [34], suggesting that IL-37 might play an inhibiting role in EOC. So, more studies are needed to discuss the disease in wider range and population to confirm the results. Finally, in this EOC study, only IL-37 level of the serum was detected. Detection of IL-37 expression in EOC tissues in future will make the conclusion more reliable.

The role of $\mathrm{IL}-37$ in other diseases: Preeclampsia (PE) is a pregnancy-specific disease. Its clinical manifestations are hypertension, proteinuria and edema, even convulsions and coma in severity. Southcombe JH et al. [38] found that the levels of IL-37 and IL$18 \mathrm{BP}$ in the placenta of patients with preeclampsia were significantly 
Table 1. The role of the novel cytokine IL-37 in inflammations and tumors of human reproductive system

\begin{tabular}{|c|c|c|c|c|}
\hline Organ & Disease & Expression of IL-37 & Function of IL-37 & Mechanism \\
\hline \multirow[t]{3}{*}{ Uterus } & Uterine adenomyosis & $\begin{array}{l}\text { Down (specimen glands and } \\
\text { stromal cells) }\end{array}$ & High expression may treat adenomyosis & Unknown \\
\hline & Endometriosis (EMs) & Up (serum and peritoneal fluid) & $\begin{array}{l}\text { Participate in the process of endometriosis } \\
\text { inflammation }\end{array}$ & NF- $\kappa \mathrm{B}$ and IL-37 are mutually inhibited \\
\hline & Cervical cancer(CC) & Unknown & $\begin{array}{l}\text { Inhibit the proliferation, metastasis and } \\
\text { invasion of cancer cells }\end{array}$ & Inhibition of STAT3, MMP-2 / MMP-9 \\
\hline Breast & Breast cancer & Unknown & Anti-4t1 breast cancer & $\begin{array}{l}\text { Regulate tumor microenvironment and affect } \mathrm{T} \\
\text { cell activation }\end{array}$ \\
\hline \multirow[t]{2}{*}{ Ovary } & $\begin{array}{l}\text { Polycystic ovarian syndrome } \\
\text { (PCOS) }\end{array}$ & Down (blood) & Inhibit PCOS inflammatory response & Unknown \\
\hline & Epithelial ovarian cancer(EOC) & Up (serum) & High expression indicates a poor prognosis & Unknown \\
\hline \multirow[t]{2}{*}{ Placenta } & Preeclampsia & Up (placenta) & Prevent inflammation of the mother & Unknown \\
\hline & Gestational diabetes mellitus(GDM) & Down (placenta and serum) & Protect pregnant women from GDM & Unknown \\
\hline $\begin{array}{l}\text { Testis } \\
\text { Prostate }\end{array}$ & $\begin{array}{l}\text { Varicocele } \\
\text { Prostate cancer }\end{array}$ & $\begin{array}{l}\text { Up (semen) } \\
\text { Unknown }\end{array}$ & $\begin{array}{l}\text { Inhibition of varicocele inflammatory } \\
\text { response } \\
\text { Radiosensitizer }\end{array}$ & $\begin{array}{l}\text { Binding to IL-18BP and IL-18R inhibits IL-18 } \\
\text { Unknown }\end{array}$ \\
\hline Other organs & $\begin{array}{l}\text { Oviduct, vagina, vas deferens and } \\
\text { so on }\end{array}$ & Unknown & Unknown & Unknown \\
\hline
\end{tabular}

up-regulated. In view of that Toll-like Receptors (TLRs) lead to the development of PE through TLR3 and TLR4 pathways, IL-37may affect the occurrence of PE through TLRs [39-41].

In Gestational Diabetes Mellitus (GDM), Yu et al. [42] studied the role of IL-37 and IL-38 by determining the thickness of umbilical artery, the area of capillaries in placental villi. IL-37 was significantly reduced in GDM placenta or serum while IL-38 was increased. Ultimately, their data showed that IL-37 has a positive effect on the prevention of GDM. The paper speculates that IL-38 produced by chorionic villi and umbilical cord may be caused by local inflammation in the development of GDM, and this disorder's microenvironment may lead to GDM development through immune-mediated mechanisms.

\section{IL-37 is helpful for diagnosis and therapy in male reproductive system diseases}

Few IL-37 studies were found in diseases of male reproductive system. In varicocele, Zeinali $\mathrm{M}$ et al. [43] found that the levels of IL-37 and IL-18 were significantly elevated in infertile men with varicocele, suggesting that the interaction between IL-37 and IL-18R beta can lead to decrease inflammatory response. Therefore, IL-37 may become a potential biomarker and therapeutic target for male infertility.

In prostate cancer, Ding VA et al. [44] found that although IL37 has no direct effect on prostate cancer, it can serve as a potential radiosensitizer. In the prostate cancer cells (DU145 cells), the proliferation of DU145 colonies was reduced by IL-37 treatment. In this process, up-regulation of p27 (an anti-proliferative molecule), Fas and Bax (two pro-apoptotic molecules) and down regulation of cdk-2 (a pro-proliferative molecule) were observed by RT-PCR. Interestingly, increased cyclinD (a proliferation molecule) and decreased TRAILR1 (the pro-apoptotic molecule) were also investigated. In conclusion, their study demonstrated the potential of IL-37 as a radiosensitizer for prostate cancer (Table 1).

\section{Prospects}

Although a few cues have been provided, the relationship between IL-37 and reproductive system diseases remains unclear so far. More and more studies are required in the future. In some most recent studies, the relationship between IL-37 and mast cells are paid more attention in allergy and other diseases [45-48], which also indicates that IL-37 may function through mast cells in allergic diseases of reproductive system.
The most possible directions for researchers in reproductive system contain the diagnosis and treatment for inflammatory diseases and cancer, especially in cervicitis, breast cancer, oophoroma, prostatitis and prostatic cancer because of their high incidence. During the process, these disease models are also helpful to elucidate the molecular function of IL-37. In addition, it remains unknown about how IL-37 works in embryogenesis which resulting in a hit in the world. In future, IL-37 may become potentially a marker or a drug for reproductive diseases.

\section{Acknowledgements}

This study is supported by Science and Technology Planning Project of Guangdong Province, China (2016A020215147), by Natural Science Foundation of Guangdong Province, China (2018A030307026), by Medical Science and Technology Research Fund of Guangdong province, China (A2017605), by Students' innovative experiment program of Guangdong medical university (2017ZZDS005), by student's platform for innovation and entrepreneurship training program (GDMU2016006, GDMU2016024, GDMU2016037, GDMU2017004，201710571006，201710571024，201710571037), by special funds for the cultivation of guangdong university students' scientific and technological innovation. ("Climbing Program” Special Funds) (pdjhb0225).

\section{References}

1. Nold MF, Nold-Petry CA, Zepp JA, Palmer BE, Bufler P, et al. (2010) IL-37 is a fundamental inhibitor of innate immunity. Nat Immunol 11: 1014-1022. [Crossref]

2. Godsell J, Rudloff I, Kandane-Rathnayake R, Hoi A, Nold MF, et al. (2016) Clinical associations of IL-10 and IL-37 in systemic lupus erythematosus. Sci Rep 6: 34604.

3. Song L, Qiu F, Fan Y, Ding F, Liu H, et al. (2013) Glucocorticoid regulates interleukin-37 in systemic lupus erythematosus. J Clin Immunol 33: 111-117. [Crossref]

4. Li J, Zhai Y, Ao L, Hui H, Fullerton DA, et al. (2017) Interleukin-37 suppresses the inflammatory response to protect cardiac function in old endotoxemic mice. Cytokine 95: 55-63. [Crossref]

5. Li C, Ji H, Cai Y, Ayana DA, Lv P, et al. (2013) Serum interleukin-37 concentrations and $\mathrm{HBeAg}$ seroconversion in chronic $\mathrm{HBV}$ patients during telbivudine treatment. $J$ Interferon Cytokine Res 33: 612-618. [Crossref]

6. Yan J, Zhang Y, Cheng S, Kang B, Peng J, et al. (2017) Common genetic heterogeneity of human interleukin-37 leads to functional variance. Cell Mol Immunol 14: 783-791. [Crossref]

7. Jiang JF, Xiao SS, Xue M (2018) Decreased expression of interleukin-37 in the ectopic and eutopic endometria of patients with adenomyosis. Gynecol Endocrinol 34: 83-86. [Crossref] 
8. Jiang JF, Deng Y, Xue W, Zheng TP, Sun AJ (2016) Increased Expression of Interleukin 37 in the Eutopic and Ectopic Endometrium of Patients with Ovarian Endometriosis. Reprod Sci 23: 244-248. [Crossref]

9. Kaabachi W, Kacem O, Belhaj R, Hamzaoui A, Hamzaoui K (2017) Interleukin-37 in endometriosis. Immunol Lett 185: 52-55. [Crossref]

10. Wang S, An W, Yao Y, Chen R, Zheng X, et al. (2015) Interleukin 37 Expression Inhibits STAT3 to Suppress the Proliferation and Invasion of Human Cervical Cancer Cells. J Cancer 6: 962-969. [Crossref]

11. Yang X, Wang F, Wang L, Chen L, Shi Y (2016) The inhibition of cervical carcinoma cell proliferation and infiltration by IL-37. Med One 1 .

12. Huo J, Hu J, Liu G, Cui Y, Ju Y (2017) Elevated serum interleukin-37 level is a predictive biomarker of poor prognosis in epithelial ovarian cancer patients. Arch Gynecol Obstet 295: 459-465. [Crossref]

13. Wang WQ, Zhao D, Zhou YS, Hu XY, Sun ZN, et al. (2015) Transfer of the IL-37b gene elicits anti-tumor responses in mice bearing 4T1 breast cancer. Acta Pharmacol Sin 36: 528-534. [Crossref]

14. Kumar S, McDonnell PC, Lehr R, Tierney L, Tzimas MN, et al. (2000) Identification and initial characterization of four novel members of the interleukin-1 family. $J$ Biol Chem 275: 10308-10314. [Crossref]

15. Akdis M, Burgler S, Crameri R, Eiwegger T, Fujita H, et al. (2011) Interleukins, from 1 to 37 , and interferon- $\mathrm{I}^{3}$ : receptors, functions, and roles in diseases. $J$ Allergy Clin Immunol 127: 701-721. [Crossref]

16. Taylor SL, Renshaw BR, Garka KE, Smith DE, Sims JE (2002) Genomic organization of the interleukin-1 locus. Genomics 79: 726-733. [Crossref]

17. Sedimbi SK1, Hagglof T, Karlsson MC (2013) IL-18 in inflammatory and autoimmune disease. Cell Mol Life Sci 70: 4795-4808. [Crossref]

18. Dinarello C, Novick D, Kim S, Kaplanski G (2013) Interleukin-18 and IL-18 binding protein. Front Immunol 4: 289. [Crossref]

19. Tough DF, Zhang X, Sprent J (2001) An IFN-gamma -Dependent Pathway Controls Stimulation of Memory Phenotype CD8 ${ }^{+} \mathrm{T}$ Cell Turnover In Vivo by IL-12, IL-18, and IFN-gamma. J Immunol 166: 6007-6011.

20. Arend WP, Palmer G, Gabay C (2008) IL-1, IL-18, and IL-33 families of cytokines. Immunol Rev 223: 20-38. [Crossref]

21. Ghayur T, Banerjee S, Hugunin M, Butler D, Herzog L, et al. (1997) Caspase-1 processes IFN-gamma-inducing factor and regulates LPS-induced IFN-gamma production. Nature 386: 619-623. [Crossref]

22. Wei XQ, Leung BP, Niedbala W, Piedrafita D, Feng GJ, et al. (1999) Altered Immune Responses and Susceptibility to Leishmania major and Staphylococcus aureus Infection in IL-18-Deficient Mice. J Immunol 163: 2821-2828. [Crossref]

23. Bulau AM, Nold MF, Li S, Nold-Petry CA, Fink M, et al. (2014) Role of caspase-1 in nuclear translocation of IL-37, release of the cytokine, and IL-37 inhibition of innate immune responses. Proc Natl Acad Sci U S A 111: 2650-2655. [Crossref]

24. Sharma S, Kulk N, Nold MF, Graf R, Kim SH, et al. (2008) The IL-1 Family Member $7 \mathrm{~b}$ Translocates to the Nucleus and Down-Regulates Proinflammatory Cytokines. $J$ Immunol 2008, 180, 5477-5482. [Crossref]

25. Trotta R, Dal Col J, Yu J, Ciarlariello D, Thomas B, et al. (2008) TGF-beta Utilizes SMAD3 to Inhibit CD16-Mediated IFN-gamma Production and Antibody-Dependen Cellular Cytotoxicity in Human NK Cells. J Immunol 181: 3784-3792. [Crossref]

26. Laouar Y, Town T, Jeng D, Tran E, Wan Y, et al. (2008) TGF-beta signaling in dendritic cells is a prerequisite for the control of autoimmune encephalomyelitis. Proc Natl Acad Sci U S A 105: 10865-10870. [Crossref]

27. Harrison DA (2012) The Jak/STAT pathway. Cold Spring Harb Perspect Biol 4. [Crossref]

28. Zhang H, Wang W, Fang H, Yang Y, Li X, et al. (2014) GSK-3beta inhibition attenuates CLP-induced liver injury by reducing inflammation and hepatic cell apoptosis. Mediators Inflamm 2014: 629507.
29. Kim KD, Zhao J, Auh S, Yang X, Du P, et al. (2007) Adaptive immune cells temper initial innate responses. Nat Med 13: 1248-1252. [Crossref]

30. De Toni L, Menaldo D, Cintra A, Figueiredo M, de Souza A, et al. (2015) Inflammatory mediators involved in the paw edema and hyperalgesia induced by Batroxase, a metalloproteinase isolated from Bothrops atrox snake venom. Int Immunopharmacol 28: 199-207. [Crossref]

31. Li TT, Zhu D, Mou T, Guo Z, Pu JL, et al. (2017) IL-37 induces autophagy in hepatocellular carcinoma cells by inhibiting the PI3K/AKT/mTOR pathway. Mol Immunol 87: 132-140. [Crossref]

32. Yan X, Zhao J, Zhang R (2017) Interleukin-37 mediates the antitumor activity in colon cancer through ß-catenin suppression. Oncotarget 8: 49064-49075. [Crossref]

33. Fan Y, Chen H, Chen W, Liu Y, Fu Y, et al. (2018) Expression of inflammatory cytokines in serum and peritoneal fluid from patients with different stages of endometriosis. Gynecol Endocrinol 34: 507-512. [Crossref]

34. Aytan AN, Bastu E, Demiral I, Bulut H, Dogan M, Buyru F (2016) Relationship between hyperandrogenism, obesity, inflammation and polycystic ovary syndrome. Gynecol Endocrinol 32: 709-713. [Crossref]

35. Ge G, Wang A, Yang J, Chen Y, Yang J, et al. (2016) Interleukin-37 suppresses tumor growth through inhibition of angiogenesis in non-small cell lung cancer. $J$ Exp Clin Cancer Res 35: 13. [Crossref]

36. Jiang Y, Wang Y, Liang L, Gao Y, Chen J, et al. (2015) IL-37 mediates the antitumor activity in renal cell carcinoma. Med Oncol 32: 250. [Crossref]

37. Schildkraut JM, Schwingl PJ, Bastos E, Evanoff A, Hughes C (1996) Epithelial ovarian cancer risk among women with polycystic ovary syndrome. Obstet Gynecol 88: 554559. [Crossref]

38. Southcombe JH, Redman CW, Sargent IL, Granne I (2015) Interleukin-1 family cytokines and their regulatory proteins in normal pregnancy and pre-eclampsia. Clin Exp Immunol 181: 480-490. [Crossref]

39. Chatterjee P, Weaver LE, Chiasson VL, Young KJ, Mitchell BM (2011) Do doublestranded RNA receptors play a role in preeclampsia? Placenta 32: 201-205. [Crossref]

40. Koga K, Mor G (2010) Toll-like receptors at the maternal-fetal interface in norma pregnancy and pregnancy disorders. Am J Reprod Immunol 63: 587-600. [Crossref]

41. Bouças AP, de Souza BM, Bauer AC, Crispim D (2017) Role of Innate Immunity in Preeclampsia: A Systematic Review. Reprod Sci 24: 1362-1370. [Crossref]

42. Yu Z, Liu J, Zhang R, Huang X, Sun T, et al. (2017) IL-37 and 38 signalling in gestational diabetes. J Reprod Immunol 124: 8-14. [Crossref]

43. Zeinali M, Hadian Amree A, Khorramdelazad H, Karami H, Abedinzadeh M (2017) Inflammatory and anti-inflammatory cytokines in the seminal plasma of infertile men suffering from varicocele. Andrologia 2017, 49. [Crossref]

44. Ding VA, Zhu Z, Steele TA, Wakefield MR, Xiao H, et al. (2017) The novel role of IL-37 in prostate cancer: evidence as a promising radiosensitizer. Med Oncol 35: 6 . [Crossref]

45. Mastrangelo F, Frydas I, Ronconi G, Kritas SK, Tettamanti L, et al. (2018) Low-grade chronic inflammation mediated by mast cells in fibromyalgia: role of IL-37. $J$ Biol Regul Homeost Agents 32: 195-198. [Crossref]

46. Caraffa A, Conti C, D Ovidio C, Gallenga CE, Tettamanti L, et al. (2018) New concepts in neuroinflammation: mast cells pro-inflammatory and anti-inflammatory cytokine mediators. J Biol Regul Homeost Agents 32: 449-454. [Crossref]

47. Majewski K, Agier J, KozA, owska E, Brzezi A, et al. (2018) Status of cathelicidin IL37 , cytokine TNF, and vitamin D in patients with pulmonary tuberculosis. $J$ Biol Regul Homeost Agents 32: 321-325. [Crossref]

48. Kritas SK, Gallenga CE, D Ovidio C, Ronconi G, Caraffa A, et al. (2018) Impact of mold on mast cell-cytokine immune response. J Biol Regul Homeost Agents 32: 763768. [Crossref]

Copyright: (C2018 Zhao J. This is an open-access article distributed under the terms of the Creative Commons Attribution License, which permits unrestricted use, distribution, and reproduction in any medium, provided the original author and source are credited. 